\title{
Konstruksi Makna Jurnalis Foto Kebencanaan dalam Karya Foto Jurnalistik
}

\author{
Bayu Anggara*, Yadi Supriadi \\ Fakultas Ilmu Komunikasi, Universitas Islam Bandung, Indonesia \\ *bayuanggara0610@gmail.com, supriadias71@gmail.com
}

\begin{abstract}
Journalists are one of the professions that demands a honesty and fairness for the culprit, because the journalist is as one the real form of information through media for a wide audience in the process of delivering messages through the mass media. Competent journalists must master the science of Communication in both the mass Communication, communication psychology, sociology of communication, philosophy, politics, social and cultural communication. The responsibility of a journalist should always be based on the truth and to be fought. A journalist under any circumstances is required to high the instinct and its sensitivity to the situation in the field as a photojournalist assigned to the disaster area. Photos is a medium with a strong image or visual message content to provide information for a wide audience so that every human being in the community can feel and know the reality that occurs in the field that Portrayed by a photo journalist. The purpose of this research is how the authors will examine how the construction of the meaning of a photojournalist in a solution in the disaster area with a qualitative method with a phenomenological approach using the theory of Alfred Schutz. The results of this study concluded that the construction of photojournalist in the Media Indonesia news papper is on the basis of social awareness of individual photo journalism by analyzing the situation and conditions in the field with Armed with experience and flying hours from each photo journalist in the program and become one of the living witnesses of the historical part of a natural disaster event that occurred by capture it through the camera lens as a medium of delivering the message to a wider audience.
\end{abstract}

Keywords: Social Construction, The Meaning of Photojournalist, Disaster Photo Coverage, Phenomenology

Abstrak. Wartawan adalah salah satu profesi yang menuntut sebuah kejujuran dan keadilan bagi para pelakunya, sebab wartawan adalah sebagai salah-satu bentuk nyata sebuah informasi melalui media bagi khalayak luas dalam proses penyampaian pesan melalui media massa. Wartawan yang berkompeten harus menguasai ilmu komunikasi. Tanggung jawab seorang wartawan harus selalu berpijak pada kebenaran dan harus diperjuangkan. Seorang wartawan dalam kondisi apapun dituntut untuk menjungjung tinggi insting dan kepekaannya terhadap situasi di lapangan salah satunya menjadi wartawan foto yang ditugaskan di daerah kebencanaan. Foto merupakan sebuah media dengan kandungan pesan gambar atau visual guna yang kuat untuk memberikan informasi bagi khalayak luas agar setiap insan manusia di lingkungan masyarakat dapat merasakan serta mengetahui realitas yang terjadi di lapangan yang digambarkan oleh seorang pewarta foto. Tujuan dari penelitian ini adalah bagaimana penulis akan meneliti bagaimana konstruksi makna seorang jurnalis foto dalam peliputannya di daerah kebencanaan dengan metode kualitatif dengan pendekatan fenomenologi menggunakan teori Alfred Schutz. Hasil penelitian ini menyimpulkan bahwa konstruksi jurnalis foto dalam peliputan foto kebencanaan di Harian Media Indonesia atas dasar kesadaran sosial dari masingmasing individu pewarta foto dengan menganalisis situasi dan kondisi di lapangan dengan berbekal pengalaman dan jam terbang dari setiap pewarta foto dalam peliputannya dan menjadi salah satu saksi hidup dari bagian sejarah sebuah peristiwa bencana alam yang terjadi dengan mengabadikannya melalui lensa kamera sebagai medium penyampaian pesan kepada khalayak luas.

Kata Kunci: Konstruksi Sosial, Makna Jurnalis Foto, Peliputan Foto Kebencanaan, Fenomenologi 


\section{A. Pendahuluan}

Wartawan ialah sebagai salah satu informasi melalui media bagi khalayak luas dalam penyampaian pesan melalui media. Tugas utama seorang wartawan sebagai pengumpul, pencari, pemilih, pengolah, dan penyaji berita secepatnya dengan memiliki daya gerak (vitalisasi), disajikan dengan gaya bahasa yang hidup dan lincah, sederhana atau lebih dikenal dengan gaya Bahasa populer.

Dalam prosesnya, wartawan yang berkualitas tentunya harus menguasai ilmu komunikasi bagian komunikasi massa, psikologi komunikasi, sosiologi komunikasi, filsafat komunikasi politik sosial budaya, sejarah perkembangan jurnalistik, banyak membaca, menguasai berbagai ragam Bahasa, teknik penyajian dan mengetahui sifat- sifat yang mudah untuk digunakan. Syarat sebagai seorang pewarta harus memiliki otonomi sendiri dan mengatur diri sendiri dengan kemampuan sendiri.

Maka dari itu peneliti memilih untuk meneliti makna dari konstruki identitas seorang jurnalis foto kebencanaan dalam karya foto jurnalistik di daerah bencana alam gempa bumi Lombok Utara, Nusa Tenggara Barat. Proses interaksi inilah yang akan menimbulkan pemaknaan konstruksi identitas seorang wartawan setelah mengambil foto di daerah kebencanaan. Peneliti ingin mengetahui pendekatan seorang wartawan foto dan perubahan apa yang terjadi setelah berada di daerah bencana. Karena sebuah proses interaksi antara wartawan dan masyarakat Lombok Utara termasuk dalam ranah komunikasi.

Pada perumusan masalah ini, peneliti melihat pengalaman dari motif dan pemaknaan itu sendiri pada pendekatan fenomenologi menurut Alfred Schutz.

Berdasarkan latar belakang diatas, maka perumusan masalah dalam penelitian ini adalah: "Bagaimana Konstruksi Makna Jurnalis Foto Kebencanaan dalam Karya Foto Jurnalistik?"

1. Bagaimana motif profesi wartawan dalam peliputan foto kebecanaan?

2. Bagaimana pengalaman profesi wartawan dalam peliputan foto kebencanaan?

3. Bagaimana pemaknaan secara verbal atau non-verbal profesi wartawan dalam peliputan foto kebencanaan?

\section{B. Landasan Teori}

Dalam penelitian ini, penulis menggunakan metode penelitian kualitatif. Penelitian kualitatif dikenal juga dengan nama penelitian naturalistik. Metode penelitian kualitatif merupakan hal yang penting bagi dasar dari disiplin ilmu khususnya ilmu-ilmu yang mengandung masalah sosial. "Penelitian kualitatif dapat mendorong sebagai lintas disiplin ilmu karena pembahasan yang cukup luas seperti pendidikan, sosiologi, psikologi, kedokteran, kebidanan hukum, politik, dan sebagainya" (Nasution, 2003: 5).

Metode kualitatif bertujuan untuk mendapatkan pemahaman tentang kenyataan melalui proses berpikir induktif, peneliti dituntut untuk terlibat dalam situasi dan fenomena yang diteliti, tidak seperti penelitian kuantitatif di mana peneliti berada di luar lingkaran setting objek yang diteliti. Masalah yang di kaji merupakan fenomena yang terjadi terhadap konstruksi makna seorang wartawan foto di harian Media Indonesia dalam peliputan di daerah kebencanaan. Teori konstruksi sosial realitas merupakan ide atau prinsip utama dalam tradisi sosiokultural. Ide ini menyatakan bahwa dunia sosial kita tercipta karena adanya interaksi antar manusia.

Cara bagaimana kita berkomunikasi sepanjang waktu mewujudkan pengertian kita mengenai pengalaman, termasuk ide kita mengenal diri kita sebagai manusia dan komunikator (Morissan, 2013: 113-114). Menurut Stephen W. Little Jhon dalam bukunya Theories of Human Communication, "Fenomenologi berasumsi bahwa orang-orang secara aktif menginterpretasi pengalaman-pengalamannya dan mencoba memahami dunia dengan pengalaman pribadinya" (Little Jhon \& Foss, 2009:57).

Edmund Husserl (1859-1938) dalam bukunya Natanson (1966:3) yang dikutip oleh Elvinaro Ardianto \& Bambang QAness dalam bukunya, menyatakan: Fenomenologi adalah untuk memurnikan sikap alamiah kehidupan sehari-hari dengan tujuan menerjemahkannya sebagai sebuah objek untuk penelitian filsafat secara cermat dan dalam rangka menggambarkan 
serta memperhitungkan struktur esensialnya (Ardianto \& Q-Aness, 2007: 128).

Menurut kedua ahli sosiologi, Peter L. Berger dan Thomas Luckmann, teori ini dimaksudkan sebagai satu kajian teoritis dan sistematis mengenai sosiplogi pengetahuan, dan bukan sebagai suatu tinjauan historis mengenai perkembangan disiplin ilmu. Menurut Bungin, realitas sosial merupakan konstruksi sosial yang diciptakan oleh individu. Individu adalah manusia bebas yang melakukan hubungan antara manusia yang satu dengan yang lain (dalam Sukidin, 2002: 194). Ahmad DS (dalam Jurnalistik Foto, 2013:46) menjelaskan bahwa "Yang termasuk katergori headline adalah berita yang amat menarik, memikat dan menimbulkan rangsangan pembaca untuk membacanya sampai habis".

Selain menarik, headline hendaknya memenuhi syarat sebagai berita yang penting, bahkan terpenting. Dengan demikian, foto-foto yang menyertai headline sebuah surat kabar pada umumnya termasuk pada foto jurnalistik. Dalam bukunya Jurnalistik Foto: Suatu Pengantar, Gani \& Kusumalestari (2014:4) mengutip dari Sudjojo (2010:6) bahwa "Fotografi sebagai teknik adalah mengetahui cara-cara memotret dengan benar, mengetahui cara-cara mengatur pencahayaan, mengetahui caracara pengolahan gambar yang benar, dan semua yang berkaitan dengan fotografi sendiri."

Sedangkan fotografi sebagai karya seni mengandung nilai estetika yang mencerminkan pikiran dan perasaan dari fotografer yang ingin menyampaikan pesannya melalui gambar/foto. Fotografi tidak bisa didasarkan pada berbagai teori tentang bagaimana memotret saja karena akan menghasilkan gambar yang sangat kaku, membosankan dan tidak memiliki rasa.

Fotografi harus disertai dengan seni. Sesuai dengan apa yang di definisikan oleh Wijaya (2011: 10) yang dimaksud foto jurnalistik adalah "Foto yang bernilai berita atau foto yang menarik bagi pembaca tertentu, dan informasi tersebut disampaikan kepada masyarakat sesingkkat mungkin."

Secara umum, foto jurnalistik merupakan gambar yang dihasilkan lewat proses fotografi untuk menyampaikan suatu pesan, informasi, cerita suatu persitiwa yang menarik bagi publik dan disebarluaskan lewat media massa.

\section{Hasil Penelitian dan Pembahasan}

\section{Motif Profesi Wartawan dalam Peliputan Foto Kebencanaan di haruan Media Indonesia}

Dalam konteks fenomenologi pewarta foto adalah aktor yang melakukan tindakan sosial. Para pewarta tersebut memiliki pengalaman cukup lama dalam peliputan foto di daerah kebencanaan. Mengikuti pemikiran Schutz, perilaku manusia dipengaruhi oleh dua fase, yaitu motif yang berorientasi ke masa depan (in order to motive) dan motif berorientasi ke masa lalu (because motives). Seiring dengan pemikiran Schutz, para narasumber sebagai pewarta foto yang berangkat ke daerah kebencanaan di pengaruhi oleh kedua fase tersebut. Yang dimaksud dua fase tersebut meliputi sebab dan tujuan.

1. Motif Hobi: dalam dunia fotografi sudah menjadi salah satu daya tarik bagi setiap orang, baik saat masih dalam bangku kuliah ataupun dalam dunia pekerjaan. Motif ini menjelaskan jika seorang pada dasarnya memang sudah menyukai satu bidang yaitu fotografi memang membutuhkan sesuatu untuk dipelajari secara lebih mendalam. Fotografi mempunyai banyak hal yang bisa ditemukan atau digali untuk menjadi sesuatu yang menarik. Bagi seorang pewarta foto, visualisasi dalam bentuk gambar dapat menyampaikan berjuta pesan di dalamnya.

2. Motif Sosial: merupakan faktor penentu dari terbentuknya makna diri seorang pewarta foto. Karena motif ini memiliki arti yang sangat luas, tidak hanya bagi pelaku namun juga bagi orang-orang di sekitarnya sampai khalayak luas. Disini peneliti melihat motif sosial hadir karena motif ini menunjukan bahwa tujuan yang ingin dicapai mempunyai interaksi dengan orang lain.

3. Motif Pengalaman: salah satu hal yang mendasar dari seorang pewarta foto di daerah kebencanaan. Hal ini akan timbul dari dampak sosial yang berada dalam ruang lingkup seorang pewarta foto, atas dasar pengalaman dan jam kerja di lapangan bagi seorang pewarta. 
Pemaknaan Secara Verbal atau Non Verbal Profesi Wartawan Dalam Peliputan Foto Kebencanaan di Harian Media Indonesia pada hakikatnya setiap orang memiliki caranya tersendiri untuk mendapatkan suatu informasi atau data mengenai sebuah peristiwa yang terjadi.

Komunikasi yang digunakan oleh para informan mencerminkan makna diri mereka dalam proses peliputan dengan bekal pengalaman mereka yang telah dimiliki tidak sepenuhnya dengan hasil yang di dapat dari wawancara dengan informan. Peneliti dalam penelitian ini menggunakan teori konstruksi sosial. Hal ini menyatakan bahwa dunia sosial kita tercipta karena adanya interaksi antar-manusia.

Cara bagaimana kita berkomunikasi sepanjang waktu mewujudkan pengertian kita mengenai pengalaman, termasuk ide kita mengenal diri kita sebagai manusia dan komunikator (Morissan, 2013: 113-114).

Tindakan dimulai dari dorongan hati yang melibatkan persepsi dan pemberian makna, latihan mental, pertimbangan alternatif, hingga penyelesaian (Morrisan, 2013: 224-231).

Dengan demikian dapat dikatakan bahwa kedua orang informan memiliki cara masingmasing dalam menyikapi makna secara verbal dengan masyarakat dalam peliputan foto kebencanaan. Memaknai wartawan dengan verbal tidak harus menempatkan diri "menyamar" karena bentuk memiliki bentuk lain yaitu dengan menjadi saksi mata dan menyampaikan langsung melalui foto dan ditambahkan caption. Peniliti anggap para informan sudah memahami dalam proses memaknai verbal dan nonverbal seorang pewarta foto dalam peliputan di daerah kebencanaan.

\section{Pengalaman Profesi Wartawan Dalam Peliputan Foto Kebencanaan di Harian Media Indonesia}

Dalam penelitian ini, peneliti juga akan mencari pengalaman dari pewarta foto yang dilihat selama melakukan observasi dan wawancara baik secara langsung, by phone atau melalui surat atau pesan elektronik. Penelitian dengan pendekatan fenomenologi bertujuan untuk mencari pemaknaan konstruksi seorang pewarta foto dalam peliputanya di daerah kebencanaan.

Pengalaman memungkinkan seseorang menjadi tahu dan hasil tahu ini kemudian disebut pengetahuan. Peneliti akhirnya membagi dua kategori dari pewarta foto kebencanaan di harian Media Indonesia guna menjawab pertanyaan ketiga dalam penelitian ini. Pembagian kedua kategori ini tersebut berdasarkan kualitas dari informan yang telah diwawancarai secara mendalam oleh penulis.

1. Pengalaman Positif

2. Pengalaman Negatif

\section{Kesimpulan}

Secara keseluruhan, para informan menjelaskan motif mereka dalam mengartikan dirinya sebagai perofesi seorang wartawan foto dengan kebutuhan mereka masing-masing. Dari kedua informan ini mengatakan bahwa dari hobi fotografi lah mereka menjadi seorang pewarta foto. Dalam fotografi hal ini bisa dijadikan sebagai pesan visual yang menunjukkan suasana di lapangan, ada juga yang mengatakan jika menjadi seorang pewarta foto di daerah kebencanaan motif utama yang mendasari untuk berangkat ke daerah kebencanaan adalah motif sosial.

Motif sosial ini didasari oleh banyaknya masyarakat yang tidak menyadari kondisi di sekitarnya dan terlalu asik dengan indivdualnya masingmasing, sehingga tidak tahu apa yang sedang terjadi di sekitarnya karena motif sosial sangatlah luas dan tidak bisa diambil hanya dari satu sudut pandang saja karena dengan motif sosial ini para pewarta foto yang berangkat ke daerah kebencanaan untuk memberikan informasi kepada masyarakat luas untuk menyampaikan kebenaran. Hal ini terjadi karena banyaknya isu-isu yang tidak tersampaikan secara utuh.

Motif yang mendukung lainnya yaitu pengalaman seorang pewarta foto ketika di lapangan, pewarta foto pun tidak luput dari pemikiran yang matang ketika akan ditugaskan ke daerah kebencanaan karena ada beberapa tahapan yang harus dilakukan, riset ketika sebelum berangkat adalah hal utama dari seorang pewarta ketika berangkat ke daerah kebencanaan. Beberapa motif yang telah disampaikan tadi menjadi modal dasar seorang pewarta foto untuk 
bisa berangkat tugas ke daerah kebencanaan karena awal dari profesi seorang pewarta salah satunya pewarta foto adalah kesadaran perasaan dan pemikiran terhadap kondisi yang sedang terjadi di sektiarnya.

Penulis berpendapat jika motif dari konstruksi seorang pewarta foto untuk meliput di daerah kebencanaan, harus memiliki dasar yang kuat karena dalam perbedaan budaya dan aturan dalam peliputan di setiap daerah dan motif ini pun bisa di katakan kebutuhan fitrah mereka, yaitu informasi, sehingga mereka memikirkan cara tersendiri untuk mewujudkan informasi yang ideal bagi dirinya sendiri dan bagi masyarakat luas.

Dari data hasil wawancara dengan ketiga informan dapat ditarik kesimpulan jika secara tidak langsung mereka berada di lapangan. Pewarta foto menyikapi dirinya denga beberapa tindakan baik verbal ataupun non verbal dengan tujuan untuk berbaur dengan masyarakat ketika bertugas di daerah kebencanaan hal ini membantu mereka dalam pencarian berita yang memang sulit untuk dijangkau agar mendapatkan gambar yang maksimal.

Namun, terkadang tindakan ini menimbulkan resiko yang sangat besar, karena pada dasarnya ketika kondisi dalam peliputan di daerah kebencanaan wartawan memiliki beberapa peraturan dan ketentuan khusus untuk mengabadikan momen.

\section{E. Saran}

\section{Saran Teoritis}

Peneliti mengharapkan penelitian ini dapat menjadi rujukan bagi penelitian lain yang akan melakukan penelitian sejenis dengan menggunkanan pendekatan fenomenologi. Selain itu penelitian ini diharapkan dapat memperkaya penelitian di bidang Ilmu Komunikasi khususnya di bidang kajian Ilmu Jurnalistik dan memberikan rekomendasi yag baik dalam penelitian kualitatif

\section{Saran Praktis}

Saran dari peneliti kepada pewarta foto yang selalu ditugaskan untuk di daerah kebencanaan atau teruslah berjuang dan tetap kepada kode etik sebagai jurnalis dan tetap memberikan pendidikan kepada masyarakat luas. Semoga bisa menginspirasi kepada generasi-generasi muda lainnya yang ingin mengeakan nilai sosial yang tinggi dan menjadi saksi dari sejarah setiap waktunya dengan mengabadikam suatu sejarah ke dalam bingkai seorang wartawan.

\section{Daftar Pustaka}

[1] Effendy, Onong Uchjana. 1993. Ilmu, Teori dan Filsafat Komunikasi, Bandung: PT. Citra Aditya Bakti.

[2] Gani, Rita dan Ratri Rizki K. 2013. Jurnalistik Foto Suatu Pengantar. Bandung: Simbiosa Rekatama Media.

[3] Kuswarno, Engkus. 2009. Metodologi Penelitian Komunikasi FENOMENOLOGI

[4] Littlejohn, Stephen W dan Karen A. Foss. 2009. TEORI KOMUNIKASI Theories of Human Communication. Jakarta: Salemba Humanika.

[5] Nasution, S. 2003. Metode Penelitian Naturalistik-Kualitatif. Bandung: Tarsito. Miles, B.B. dan A.M.Huberman.1992. Analisa Data Kualitatif. Jakarta: UI Press.

[6] Morissan. 2013. Teori Komunikasi Individu Hingga Massa. Jakarta: Prenada Media Group.

[7] Moleong, Lexy J. 2005. Metodologi Penelitian Kualitatif. Edisi Revisi. Bandung: PT. Remaja Rosdakarya.

[8] Mulyana, Deddy. 2001. Ilmu Komunikasi, Suatu Pengantar. Bandung: Remaja Rosdakarya.

[9] Mulyana, Deddy. 2004. Metodologi Penelitian Kualitatif. Bandung: Remaja Rosdakarya. 
[10] Raco, J. R. 2010. Metode Penelitian Kualitatif Jenis, Karakter, dan Keunggulannya. Jakarta: Grasindo.

[11] Rakhmat, Jalaludin. 2005. Psikologi Komunikasi, Edisi Revisi. Bandung: Remaja Rosdakarya.

[12] Ritzer, George. 2001. Sosiologi Ilmu Berparadigma Ganda. Jakarta: PT Rajawali Press.

[13] Romli, Asep Syamsul M. 2012. Jurnalistik Online: Panduan Mengelola Media Online. Bandung: Nuansa 